\title{
Esfera pública, reconhecimento e minorias: o diálogo Habermas-Fraser
}

\author{
Public Sphere, Recognition and \\ Minorities: the Habermas-Fraser Dialogue
}

\author{
Maria Eugenia Bunchaft*
}

Resumo:Nancy Fraser delineou uma compreensão procedimental do reconhecimento que tem possibilidade de combater políticas estreitas de autenticidade de grupo. Jürgen Habermas enfatiza um modelo deliberativo e uma análise histórica da esfera pública, por meio de um aprendizado teórico que culminou em 1992, com Faktizität und Geltung. Pretendemos demonstrar, com base em Fraser e Habermas, que, diante de um contexto de exclusão do espaço público oficial, é necessário ampliar arenas discursivas, sob pena de reproduzirmos e mantermos as assimetrias dominantes. Fraser, em Scales of Justice, defende uma esfera pública transnacional na qual há uma rearticulação dos processos decisórios, superando as fronteiras dos estados nacionais territorialmente situados. Propugnamos analisar a evolução das concepções de esfera pública em Habermas e Fraser ao longo de suas trajetórias teóricas. Em Habermas, até 2011, havia uma ambiguidade que oscilava entre a abordagem fina de patriotismo constitucional e a concepção densa de autocompreensão europeia. Com efeito, pretendemos investigar como Habermas, em Sobre a constituição da Europa - um ensaio, Habermas soluciona tal ambiguidade em relação à compreensão de esfera pública, lecionando que os cidadãos, por meio da tecnologia digital e de padrões morais, avaliam as estruturas econômicas europeias, confrontando as instituições existentes com as exigências de uma justiça global. Sustentamos, com base em Habermas, que tais discussões devem ser efetivadas no interior de um Parlamento mundial composto de Estados e cidadãos.

Palavras-chave: Esfera pública; Reconhecimento; minorias; Habermas; Fraser.

* Professora do Programa de Pós-graduação em Direito da Unisinos. Pós-Doutora em Filosofia pela UFSC Doutora e Mestre em Teoria do Estado e Direito Constitucional pela PUC-Rio e-mail: mbunchaft @ig.com.br

Abstract: Nancy Fraser outlined a procedural understanding of the recognition it has possibility to fight close political group of authenticity. Jürgen Habermas emphasizes a deliberative model and a historical analysis of the public sphere, through a theoretical learning that culminated in 1992 with Faktizität und Geltung. We intend to demonstrate, based on Fraser and

SCIENTIAIURIS, Londrina, v.18,n.1,p.153-180,jul.2014 | DOI: 10.5433/2178-8189.2014v18n1p153 
Habermas, who, before a backdrop of exclusion from official public space, it is necessary to expand discursive arenas, otherwise reproduce and maintain the dominant asymmetries. Fraser, in Scales of Justice, argues for a transnational public sphere in which there is a re-articulation of decision processes, overcoming the boundaries of national states territorially located . We advocate to analyze the evolution of conceptions of the public sphere in Habermas and Fraser along their theoretical trajectories. Habermas, until 2011, there was an ambiguity that oscillated between the thin approach of constitutional patriotism and dense European conception of self .Indeed, we intend to investigate how Habermas, in On the Constitution of Europe an Essay, Habermas resolves this ambiguity in relation to the understanding of the public sphere, teaching citizens, through digital technology and moral standards, assess European economic structures collating existing institutions to the demands of global justice . We argue, based on Habermas, that such discussions should take effect within a world parliament composed of states and citizens.

Keywords: Public Sphere; Recognition; Minorities; Habermas; Fraser. 


\section{INTRODUÇÃO}

Nancy Fraser (2003a; 2003b)delineou uma compreensão procedimental sobre o reconhecimento que tem possibilidade de combater políticas estreitas de autenticidade de grupo, de forma a conferir uma estratégia coerente capaz de atender aos desafios das sociedades multiculturais. Em Scales of Justices, Fraser (2010)sublinha que a estrutura conceitual da justiça anteriormente focada na perspectiva bidimensional (redistribuição e reconhecimento), agora incorpora uma terceira perspectiva: a da representação. Esta irá complementar o instrumental de Fraser, sendo capaz de contemplar a dimensão estruturante do enquadramento da justiça em sociedades globais. Portanto, a terceira dimensão da justiça é o político, que "diz respeito à natureza da jurisdição do Estado e das regras de decisão pelas quais ele estrutura as disputas sociais". (FRASER, 2009, p. 19).

Nesse quadro teórico, não é mais suficiente elucidar sobre $o$ que é e quem são os destinatários da justiça. Nas palavras de FRASER (2009, p. 19), "ao estabelecer regras de decisão, a dimensão política também estipula os procedimentos de apresentação e resolução das disputas tanto na dimensão econômica e cultural". E conclui: "ela revela não apenas quem pode fazer reivindicações por redistribuição e reconhecimento, mas também como tais reivindicações devem ser introduzidas no debate e julgadas." (FRASER, 2009, p. 19).

Dessa maneira, raça, por exemplo, é uma categoria tridimensional situada na estrutura econômica, na ordem de status e na esfera da representação. Assim, os afrodescendentes, no Brasil, estariam submetidos tanto à injustiça na esfera da distribuição, no âmbito do reconhecimento, como na dimensão da representação, sendo que ambas as dimensões se reforçam mutuamente. Desse modo, o político é uma dimensão conceitualmente distinta da justiça que não se reduz à perspectiva econômica ou cultural, apesar de eles estarem entrelaçados. O como da justiça assume um papel constitutivo nos procedimentos democraticamente estruturados dos processos políticos decisórios e será a categoria necessária para configurar uma teoria crítica que identifica contextos de exclusão que integram os três níveis.

Jürgen Habermas (1992a) enfatiza um modelo deliberativo de reconhecimento inerente a uma moralidade pós-convencional, capaz de combater a perspectiva limitada da reificação identitária. Habermas (1962), em Strukturwandel der Öffentlichkeit, resgata a categoria esfera pública por 
meio de um método de análise sociológico e histórico. Trata-se de uma estratégia teórica que articula uma concepção ideal normativa e uma análise histórica da esfera pública, revelando a evolução conceitual do pensamento do autor por meio de um aprendizado teórico que culminou em 1992, com Faktizität und Geltung.

Fraser (1992), entretanto, contrapôs-se à esfera pública habermasiana (1962) estabelecida em Strukturwandel der Öffentlichkeit, que estaria baseada em pressupostos desiguais e excludentes em relação às mulheres e plebeus. A principal objeção, que é delineada por Fraser (1992a) ao procedimentalismo habermasiano, refere-se à existência de uma esfera pública, quando, na verdade, haveria para a autora uma multiplicidade de formas críticas de comunicação expressas em termos de "contrapúblicos". Estes constituem "arenas discursivas paralelas nas quais os membros dos grupos socialmente subordinados inventam e circulam contradiscursos para formular interpretações opostas de suas identidades, interesses e necessidades". (FRASER, 1992 p. 123).

Nesse cenário, na primeira parte do artigo, pretende-se analisar a evolução do conceito de esfera pública na obra de Habermas (1962; 1992a), desde Strukturwandel der Öffentlichkeit até Faktizität und Geltung, tratando das reformulações teóricas decorrentes das críticas dirigidas por Nancy Fraser à sua estrutura conceitual. Por meio da análise das obras Strukturwandel der Öffentlichkeit, Theorie und Práxis e Technik und Wissenschaft als Ideologie, pretende-se indagar: por que a esfera pública burguesa perde seu potencial crítico, anulando o engajamento discursivo dos cidadãos?

Em que medida a cientifização da política conduziu à anulação da participação do cidadão? É possível conceber uma esfera pública com base em um papel mais ofensivo em relação àquela estabelecida em Theorie des kommunikativen Handelns? De que maneira um modelo de eclusas delineado por Habermas (1992a) em Faktizität und Geltung - pode inspirar um processo de autodemocratização interno do sistema? Nesse particular, a primeira parte do artigo trata da evolução do conceito de esfera pública na obra habermasiana. A questão a ser respondida é: o modelo deliberativo habermasiano (1992a), estabelecido em Faktizität und Geltung, tem potencialidade para se contrapor às assimetrias econômicas, sociais, culturais e promover impactos concretos voltados para a inclusão de grupos estigmatizados? Na segunda parte do artigo, propugna-se demonstrar, com 
base em Fraser (1992) e na reformulação teórica habermasiana (1992b) que foi estabelecida no ensaio "Further Reflections on the Public Sphere", a hipótese segundo a qual, diante de um contexto de exclusão do espaço público oficial, é necessário ampliar arenas discursivas, sob pena de reproduzirmos e mantermos as assimetrias dominantes.

$\mathrm{Na}$ terceira parte do artigo, assume-se o objetivo de investigar os contornos teóricos da esfera pública internacional, que não tem os mesmos pressupostos da esfera pública nacional, na qual as leis que governam a sociedade são debatidas internamente. A solidariedade, que marca a esfera pública como conjunto de normas compartilhadas, não é uma característica da esfera pública internacional, embora isso seja suscetível de mudança. $\mathrm{Na}$ obra Sobre a Constituição da Europa: um ensaio, Habermas (2012), apesar do agravamento da crise econômica na Europa em 2011, permanece otimista, defendendo uma esfera pública cosmopolita democrática e mundial. Segundo Habermas (2012), há um temor das elites políticas de que o projeto europeu, realizado até agora por uma elite restrita de burocratas, alcance uma esfera pública mais ampla e deliberativa.

Desde Inclusion of the Other, o herdeiro da Escola de Frankfurt (1998) assinala que a construção democrática da integração europeia enfrenta grandes dificuldades. Trata-se do chamado déficit democrático, pois as instituições transnacionais possuem pouca legitimidade aos olhos dos cidadãos, porquanto as novas organizações emergem cada vez mais distantes da base política, tal como a burocracia em Bruxelas.

Justamente para superar esse déficit democrático, Habermas (1998) aposta em um patriotismo constitucional europeu, que transcenda os limites do Estado-nação, capaz de ajustar o universalismo dos direitos humanos ao particularismo das identidades culturais. Fraser (2009), em Scales of Justice, por sua vez, defende uma esfera pública transnacional na qual há uma rearticulação dos processos decisórios, superando as fronteiras dos estados nacionais territorialmente situados. As demandas por justiça não são discutidas apenas pelos públicos nacionais, e os reivindicantes não se restringem a discutir apenas as relações entre cidadãos. Pretende-se sustentar que Habermas (2012), em Sobre a Constituição da Europa: um ensaio, assume uma estrutura conceitual renovada que supera as ambiguidades teóricas anteriores, relativas ao papel da esfera pública mundial. Feitas essas considerações, passamos à análise da concepção habermasiana de esfera pública. 


\section{A CONCEPÇÃO HABERMASIANA DE ESFERA PÚBLICA}

De início, é premente lecionar que Strukturwandel der Öffentlichkeit originou-se da tese de habilitação pós-doutoral de Habermas (1962), que foi submetida a Adorno e Horkheimer, em Frankfurt. Estes consideraram que esta era pouco crítica das ilusões da concepção iluminista de espaço público democrático, especialmente em sociedades de massa. Influenciando nos primeiros anos o movimento estudantil, Strukturwandel der Öffentlichkeit inspirou uma literatura crítica que apontava para a não inserção do proletariado na esfera pública e por exagerar o potencial emancipatório da esfera pública burguesa idealizada.

Nesse quadro teórico, em Strukturwandel der Öffentlichkeit, Habermas (1962) analisa o desenvolvimento histórico da categoria esfera pública e suas transformações estruturais. As diferentes formulações da esfera pública são perpassadas por diferentes momentos históricos. Analisa a gênese da esfera pública no mundo grego, no mundo feudal, na sociedade burguesa e no mundo contemporâneo. Segundo Lubenow (2012), a questão fundamental era: por que o processo histórico de emancipação da esfera pública burguesa se converte em uma despolitização das massas decorrente da ausência de participação política das mesmas? Por que a esfera pública perde seu potencial crítico?

Em face desta leitura, Habermas (1962) considera dois fatores fundamentais que contribuíram para a decadência da esfera pública burguesa: o crescimento do público da esfera pública e o incremento do intervencionismo estatal. Nesse livro, a origem da esfera pública burguesa conecta-se ao desenvolvimento de uma esfera pública literária, que, mesmo não sendo uma esfera pública com caráter político, já revelava um raciocínio de caráter público. A esfera pública literária não era de fato especificamente burguesa, pois mantinha uma linha de continuidade com a publicidade decorrente da representação exercida na corte do príncipe. Surge a contraposição entre duas formas de publicidade: a publicidade representativa inerente às cortes feudais e a publicidade crítica, que expressava os ideais do iluminismo. A publicidade representativa expressava-se por uma aura que decorria da autoridade.

Desse modo, a emergência de uma esfera pública política a partir da esfera literária passa a conectar a opinião pública, o Estado e a sociedade burguesa. O surgimento de cafés, salões, centros de crítica literária - decorrentes do encontro entre os herdeiros da sociedade aristocrata e a burguesia - inspira uma esfera pública crítica. Se a esfera crítica inicialmente limitava-se à dimensão

SCIENTIAIURIS, Londrina, v.18, n.1,p.153-180, jul.2014 | DOI: 10.5433/2178-8189.2014v18n1p153 
cultural, a partir do surgimento de jornais, tornou-se possível a publicização da mesma.

Assim, à medida que as pessoas privadas dialogam entre si não apenas como proprietários, mas também como seres humanos, a humanidade da esfera pública literária serve de instância mediadora à efetividade da esfera política por meio de uma politização da cultura e da arte. Tais debates culturais irão inspirar o exercício crítico da esfera pública contra o poder do Estado. Posteriormente, a emergência dos meios de comunicação de massa desvincula a esfera pública do interesse público, conectando-se aos interesses privados. Surge um processo de despolitização, e a esfera pública perde o seu potencial crítico ativo assumindo um papel manipulativo.

Diante dessa estrutura conceitual, Habermas (1962) considera alguns fatores que produziram a perda da função crítica e do potencial democrático da esfera pública. $\mathrm{O}$ primeiro fator foi a interligação entre o setor público e o privado a partir de um Estado intervencionista no final do século XIX. A fronteira que distinguia entre setor público e privado na esfera pública burguesa, sofre uma reconfiguração por uma interligação progressiva entre as duas esferas. Habermas (1962) nota que elementos de direito público e de direito privado se interligam mutuamente. $\mathrm{O}$ direito de propriedade é limitado não somente por intervenções econômicas, mas também por garantias jurídicas que restabelecem a igualdade de contratar. O Estado passa a assumir um papel efetivo na economia com o objetivo de resguardar os pressupostos do sistema capitalista.

Outrossim, segundo Habermas (1962), as intervenções do Estado na esfera privada no século XIX, de um lado, visam atender aos interesses dos economicamente mais fracos. Por outro lado, serve também para atenuar os conflitos sociais. Contratos coletivos substituem os individuais, estabelecendo garantias aos parceiros mais fracos. Os meios de comunicação de massa inspiram um pseudoconsenso que anula o engajamento participativo dos cidadãos.

Em suma, o segundo elemento que impulsionou a decadência da esfera pública burguesa foi a expansão do público da esfera pública a partir da inserção das massas na política. Este fenômeno deveu-se a três eventos: a expansão do público leitor, a refuncionalização da imprensa e a expansão dos direitos políticos. Surgem interesses privados que levam à perda do potencial emancipatório da esfera pública. Habermas (1962)conclui que a esfera pública parece perder a força de seu princípio, a publicidade crítica, à medida que se amplia enquanto esfera. Consequentemente, há uma substituição de um público pensador de cultura para um público consumidor de cultura. Há uma refuncionalização 
comercial da participação das massas na esfera pública, que perde seu caráter politíco. A cultura difundida por intermédio dos meios de comunicação de massa assume funções de propaganda.

Em síntese, surge uma esfera social repolitizada que não se adequa sociológica ou juridicamente nem às categorias do público, nem às do privado. Nessa esfera intermediária, há uma interpenetração entre os setores estatizados da sociedade e os setores socializados do Estado sem a intermediação das pessoas privadas. As reivindicações das pessoas privadas, enquanto consumidores e eleitores, acabam sendo influenciadas por autoridades econômicas e políticas.

De fato, o nexo originário entre esfera íntima e esfera pública literária inverteu-se, inspirando um esvaziamento publicitário-jornalístico da esfera privada. O consumo cultural é um instrumento da propaganda econômica e política. A integração entre setor público e privado passa a ser exercida por instituições como associações, que exercem o poder em articulação com o aparelho estatal. O jornalismo crítico é substituído pelo jornalismo manipulativo que, além de influenciar o consumo, funciona como instrumento de pressão política.

Sob esse prisma, após Strukturwandel der Öffentlichkeit, Habermas $(1962,1971,1968)$ introduz em sua estrutura teórica atinente à discussão sobre a esfera pública, especificamente no prefácio à edição de 1971 de Theorie und Práxis e, em Technik und Wissenschaft als Ideologie, uma terceira inovação: a interligação entre técnica e ciência. A estratégia teórica do autor nesses ensaios teóricos é abordar em que medida a cientifização da política inspirou a questão do esvaziamento da participação política do cidadão.

Sob essa ótica, em Technik und Wissenschaft als Ideologie, Habermas (1968) interpreta a interconexão entre Estado e sociedade civil como um fenômeno produzido pelos processos de racionalização e burocratização do Estado intervencionista em sociedades capitalistas avançadas, pautadas pelo crescimento da tecnocracia. Essa nova configuração político-econômica decorreu da substituição do capitalismo liberal pelo capitalismo intervencionista, marcado pela burocratização e por uma interligação entre ciência e técnica. Agora, a categoria da esfera pública é explicada por meio da diferenciação entre duas formas de ação.

Na década de 1970, Habermas (1973) estabelece uma nova estrutura teórica quanto à categoria esfera pública, partindo de uma perspectiva dualista de sociedade. As sociedades capitalistas avançadas subdividem-se em sistemas 
sócio-culturais, políticos e econômicos. A distinção entre ação comunicativa e ação instrumental seria o pressuposto da estrutura conceitual futura, que pressuporia uma perspectiva dualista entre sistema e mundo da vida. A legitimação tecnocrática pressuposta pela exclusão de questões práticas da esfera pública inspira a lealdade das massas, despolitizando os cidadãos, que passam a atuar segundo um sistema de ação racional dirigida a fins. A inexistência de participação democrática impede a conscientização das contradições do sistema capitalista.

Nesse ponto, em Legitimationsproblem im Spätkapitalismus, Habermas (1973) introduz, pela primeira vez, os conceitos de sistema e mundo da vida. No capitalismo avançado, o Estado passa a assumir um papel mais ativo na economia, superando o capitalismo liberal. Os mecanismos autodestrutivos do mercado são corrigidos pelo intervencionismo estatal, visando controlar as crises econômicas. No entanto, tal intervencionismo estatal nas sociedades capitalistas avançadas não consegue superar as contradições do sistema no sentido de resguardar crescimento econômico, evitando crises e protegendo socialmente o cidadão. (HABERMAS, 2003, p. 51). ${ }^{1}$

Sob esse aspecto, os processos político-decisórios ficam desconectados da participação política do cidadão. Esse é o diagnóstico do cenário das sociedades capitalistas avançadas, que procura ser resolvido em Theorie des kommunikativen Handelns, tendo em vista a possibilidade de revigorar a esfera pública despolitizada. Em Theorie des kommunikativen Handelns, Habermas (1981) irá aprimorar a concepção dualista entre sistema e mundo da vida, partindo dos pressupostos argumentativos da ação comunicativa e da

\footnotetext{
${ }^{1}$ É mister frisar que Habermas (1973) analisa os problemas de legitimação enfrentados pelo Estado intervencionista, especificamente as crises econômicas dele resultantes. Constatando que o capitalismo avançado era marcado por crises de legitimação, o autor (1973) enfrenta o questionamento decorrente da viabilidade ou não da revigoração da esfera pública despolitizada. Se, em Strukturwandel der Öffentlichkeit, a categoria esfera pública delineada por Habermas (1962) era enfocada em uma perspectiva histórica, em Legitimationsproblem im Spätkapitalismus, passa a ser analisada pelo autor (1973) em uma dimensão normativa e socioteórica. A busca de legitimação do estado intervencionista não pressupõe a formação discursiva da vontade na esfera pública, pois o engajamento participativo do cidadão fica esvaziado, reduzindo-se à escolha dos dirigentes políticoadministrativos.

Nesse sentido, na esfera pública despolitizada, a legitimação restringe-se a dois requisitos: em primeiro lugar, o privatismo cívico, ou seja, a abstinência política articulada a uma orientação para a carreira, o lazer e o consumo, inspirando a expectativa de certas recompensas dentro do sistema (dinheiro, lazer, segurança). Em segundo lugar, a própria despolitização estrutural requer justificação, encontrando sustentação nas teorias da elite democrática (que relaciona-se às ideias de Schumpeter e Max Weber) e nas teorias sistêmicas tecnocráticas (que remontam ao institucionalismo da década de 1920).
}

SCIENTIAIURIS, Londrina, v.18, n.1,p.153-180, jul.2014 | DOI: 10.5433/2178-8189.2014v18n1p153 
centralidade das pretensões de validade. Agora, as potencialidades da ação comunicativa tornam-se o centro da discussão, substituindo a análise historiográfica. Há uma reabilitação da esfera pública sob uma configuração teórica renovada voltada para a tentativa de democratização.

Indubitavelmente, para Habermas (1981), é a ação comunicativa que garante a integração social, sendo um mecanismo capaz de freiar as invasões sistêmicas. $\mathrm{O}$ conceito de mundo da vida, vinculado à fenomonologia, inspira uma nova racionalidade e uma esfera pública que tem como base teórica a pragmática da linguagem a partir do instrumental de Austin (apud Habermas, 1981) e Wittgenstein (apud Habermas, 1981) e da fenomonologia. É no mundo da vida que surgem práticas dialógicas que suscitam integração social, reprodução cultural e socialização.

Portanto, a sociedade civil é o aspecto institucional do mundo da vida que não se confunde com o elemento linguístico e simbólico. Habermas (1981), em Theorie des kommunikativen Handelns, parte de uma visão dualista entre mundo da vida e sistema, que se reflete na diferenciação entre ação instrumental e ação comunicativa. Os mecanismos sistêmicos do dinheiro, poder e direito vão invadindo, de forma colonizadora, o mundo da vida, restringindo a rede intersubjetiva das práticas comunicativas. Agora, a coordenação de ação não se orienta por pressupostos discursivos, mas por dinheiro ou poder. A esfera pública transforma-se em um domínio marcado pela monetarização, burocratização e juridificação.

Nesse quadro teórico, em Theorie des kommunikativen Handelns, a esfera pública era constitutiva do mundo da vida, tendo a "função simbólica de integração social e de assegurar a autonomia do mundo da vida frente ao sistema administrado." (LUBENOW, 2007, p. 173). A ideia é preservar seu caráter de independência face às invasões do poder administrativo. Assumia, entretanto, um papel defensivo, sem pretensão de conquista.

Na segunda metade da década de 1980, no prefácio à terceira edição de Theorie des kommunikativen Handelns, Habermas (1985) começa a renovar sua estrutura conceitual e refere-se à ideia da relevância de um revigoramento do institucional por intermédio de um refluxo do mundo da vida. Ou seja, a relação entre sistema e mundo da vida não seria mais de um fluxo de mão única, mas passaria a incorporar a ideia de um duplo fluxo entre sistema e mundo da vida.

Com efeito, a renovação teórica fundamental sobre a concepção de esfera pública é estabelecida no prefácio de 1990 à Strukturwandel der Öffentlichkeit 
(1990), mas o seu papel mais proeminente é ampliado em Faktizität und Geltung (1992a). No prefácio de 1990, a Strukturwandel der Öffentlichkeit, a questão fundamental é: a sociedade civil tem potencialidade de mobilizar impulsos comunicativos racionalizados na esfera pública e direcioná-los ao poder político-administrativo?

Desse modo, segundo LUBENOW (2007, p. 179), no prefácio de 1990, a questão fundamental era "pensar um modelo de esfera pública não apenas defensivo, mas também da inversão da direção dos fluxos de comunicação que se entrecruzam na esfera pública, de influência e efetivação do potencial político do modelo comunicativo de esfera pública nos arranjos políticoinstitucionais". Trata-se de esferas públicas autônomas que não fazem parte do sistema político administrativo, mas "que articulam e organizam influência política por meios públicos de comunicação, participação e deliberação, contribuindo, assim, para a tematização, discussão pública e tomada de decisões". (LUBENOW, 2012, p. 202).

Nesse momento, segundo Lubenow (2007), a estratégia teórica de Habermas (1990), em Vorwortzur Neuauflage, é focar também os mecanismos institucionais constitutivos do funcionamento do ordenamento político. Não obstante, como sublinha Lubenow, "o conteúdo normativo de um conceito de democracia não pode se restringir a arranjos constitucionais do Estado Constitucional Democrático. Por isso, a referência à discussão da esfera pública vinculada à redescoberta da sociedade civil". (LUBENOW, 2007, p. 180).

No entanto, tal reviravolta teórica ainda não contempla claramente o nexo entre as esferas públicas informais e a formal, como ambas se relacionam e como fluxos comunicativos que emergem do mundo da vida alcançam o podem administrativo. Nesse momento, Habermas (1990) interpreta a esfera pública como voltada para dois processos: um comunicativo, que legitima o poder político, e um com intuitos manipulativos. Apesar de tais aportes teóricos, sobretudo no que se refere à ênfase nos mecanismos institucionais e na ideia de sociedade civil, a esfera pública delineada em Vorwort zur Neuauflage não consegue superar o modelo de sitiamento. Segundo Lubenow, Habermas (1990) reafirma de forma pessimista a incapacidade da esfera pública de se contrapor à influência dos meios de comunicação de massa.

Finalmente, em Faktizität und Geltung, o foco de Habermas (1992a) agora não é mais a ideia de sitiamento, estabelecida pelo autor (1981) em Theorie des kommunikativen Handelns, mas um processo de 
autodemocratização interno do sistema. Nesta obra, há uma nova estrutura conceitual baseada em um modelo de eclusas que confere à esfera pública um papel mais ofensivo. Essa nova configuração teórica inspirou uma compreensão original sobre o nexo entre poder comunicativo e poder administrativo instituído no sistema político.

\section{AS CRÍTICAS DE FRASER DIRECIONADAS A HABERMAS}

Antes da proposta de Habermas (1992a) em Faktizität und Geltung, Fraser (1989), em "What's Critical about Critical Theory? The Case of Habermas and Gender", avaliava duas distinções fundamentais da concepção habermasiana (1981) de modernização das sociedades delineadas em Theorie des kommunikativen Handelns. A primeira distinção dizia respeito à contraposição entre reprodução simbólica e reprodução material das sociedades. Nesse ponto, a reprodução simbólica diz respeito a processos de aprendizagem por meio dos quais os jovens internalizam valores e compreensões de mundo compartilhadas. Trata-se de processos de reprodução simbólica relativos à socialização dos jovens, de forma a assegurar a transmissão das tradições culturais.

Nesse cenário, a reprodução material, por sua vez, ocorre mediante o trabalho social para garantir a subsistência dos indivíduos. Enquanto o trabalho social é tradicionalmente desempenhado por homens, as atividades de reprodução simbólica são normalmente realizadas pelas mulheres de forma não remunerada. A segunda distinção habermasiana (1981)diz respeito a "contextos de ação socialmente integrados" e a "contextos de ação integrados pelo sistema". O primeiro relaciona-se à busca intersubjetiva de entendimento sobre normas, valores e fins, enquanto o segundo pressupõe ações humanas voltadas para o autointeresse, em uma perspectiva utilitarista, visando a alcançar dinheiro e poder.

Nesse particular, enquanto para Habermas, a família moderna conectase a um contexto de ação socialmente integrado, o sistema capitalista representa um contexto de ação integrado sistemicamente. Nessa linha de raciocínio, Fraser (1989) considera essa distinção insatisfatória para atender à complexidade das relações de gênero. Em face desta leitura, a autora pondera que tanto a família moderna como a esfera econômica são conectadas a aspectos de consensualidade e a perspectivas estratégicas, visando a alcançar esferas de poder. Nessa perspectiva, o núcleo familiar e as instituições da 
economia são categorias complexas que articulam aspectos de consensualidade e estratégia. Nas palavras da autora, "ambas as instituições são misturas de consensualidade, normatividade e estratégia. Se elas são distinguidas com relação a modos de integração da ação, a distinção deve ser dirigida como uma diferença de grau." (FRASER, 1989, p. 117).

Diante do exposto, depreende-se que a teórica feminista (1989), em "What's Critical about Critical Theory?", procura superar a distinção habermasiana (1981) entre núcleo doméstico como um local de reprodução simbólica e local de trabalho como locus de reprodução material, pois tal distinção não atende à complexidade das sociedades modernas, resultando uma concepção simplificada das relações de gênero. Uma distinção absoluta entre ambas as esferas poderia legitimar ideologicamente uma perspectiva que considera a família como algo negativo e secundário em relação à esfera econômica. Fraser analisa que a separação entre esfera econômica e doméstica pode configurar um instrumental teórico que justifica arranjos institucionais capazes de conduzir à subordinação das mulheres.

Diante dessa estrutura conceitual, sua proposta consiste em insistir ser a esfera doméstica também uma esfera de trabalho, enquanto que algumas funções de reprodução simbólica também ocorrem nas instituições do Estado e da economia. Tanto na esfera doméstica como no local de trabalho, as mulheres seriam submissas aos homens. Nesse contexto, uma teoria da racionalização do mundo da vida necessita ser sensível aos "subpapéis de gênero". Fraser observava os diversos papéis que os indivíduos desempenham na vida social, estabelecendo a ligação entre o mundo da vida e a esfera sistêmica. Para Habermas (1981), o espaço público, enquanto esfera de participação política, envolve uma rede de formação discursiva da opinião e da vontade. O mundo da vida conecta-se ao mundo sistêmico por meio dos papéis sociais atribuídos a cada indivíduo.

Assim, para Habermas, trocas entre a esfera familiar e a economia oficial são realizadas mediante os papéis de trabalhador e consumidor por meio do dinheiro, enquanto as trocas entre o espaço público e o Estado são realizadas por meio dos papéis de cidadão e cliente do Estado de Bem Estar social, através de relações de poder.

Embora reconhecesse que Habermas (1981), em Theorie des kommunikativen Handelns, havia desenvolvido uma concepção sofisticada das relações entre instituições públicas e privadas, Fraser (1989) pondera que seu modelo não tematizava a afirmação da centralidade dos subpapéis nas 
relações de gênero. ${ }^{2}$ Portanto, nas sociedades capitalistas, as mulheres não estão ausentes no mercado de trabalho, mas elas se apresentam diferentemente dos homens em determinadas profissões femininas, como secretárias, empregadas domésticas, enfermeiras, babás, professoras primárias.

Em suma, segundo Fraser, "essas diferenças na qualidade da presença das mulheres no mercado demonstra a dissonância conceitual entre feminilidade e o papel do trabalhador no capitalismo clássico". (FRASER, 1989, p. 114). Nas palavras da autora, "o papel do trabalhador, que conecta a economia privada à família privada, em sociedades capitalistas dominadas por homens é um papel masculino". (FRASER, 1989, p. 114).

Nessa linha de raciocínio, uma crítica fundamental de Fraser (1989) a Habermas (1981) dizia respeito ao papel de educação das crianças, que não era mencionado pelo filósofo. Na sua percepção, "tal omissão é uma marca de androcentrismo e tem algumas consequências significativas. Uma consideração do papel de educação das crianças nesse contexto poderia bem apontar a relevância central do gênero para a estrutura institucional do capitalismo clássico". (FRASER, 1989, p. 114). Por conseguinte, a divisão social do trabalho que estabelece para as mulheres papéis essencialmente femininos deveria sofrer uma reformulação institucional no que se refere à desconstrução dos valores androcêntricos.

Outrossim, outra crítica fundamental que foi estabelecida em "What's Critical about Critical Theory ?" por Fraser (1989), dizia respeito à concepção de cidadão. Para Habermas (1981), o cidadão era aquele que participava do debate político por meio de processos discursivos de formação da opinião e de vontade. Entretanto, tal capacidade de participação em práticas discursivas, para Fraser, "são conectadas com a masculinidade no capitalismo clássico dominado por homens. Elas constituem capacidades que são, em grande quantidade, negadas às mulheres e consideradas superiores à feminilidade". (FRASER, 1989, p. 115).

Nessa concepção política, a dominação masculina permeia os próprios processos deliberativos inerentes ao debate político, porquanto o papel do cidadão

\footnotetext{
2 É interessante demonstrar o posicionamento de Fraser: "Tome o papel do trabalhador. Em sociedades capitalistas clássicas, esse papel é um papel masculino e não apenas no sentido estatístico relativamente superficial. Há, diferentemente, um sentido muito profundo no qual a identidade masculina nessas sociedades é ligada ao papel de provedor. Masculinidade é, em grande parte, uma questão de deixar a casa todo dia para um local de trabalho e retornar com o sustento que fornece aos seus dependentes. É essa relação interna entre ser um homem e ser um provedor que explica porque nas sociedades capitalistas o desemprego pode ser psicologicamente e economicamente tão devastador para os homens". (FRASER, 1989, p. 113).
}

SCIENTIAIURIS, Londrina, v.18,n.1,p.153-180,jul.2014 | DOI: 10.5433/2178-8189.2014v18n1p153 
nas sociedades capitalistas é essencialmente masculino, conectando o Estado e a esfera pública e este à economia e à esfera familiar. Não obstante, o papel do cidadão é construído com base em uma identidade de gênero masculina, em contraposição a um poder de gênero neutral. ${ }^{3}$

Fraser (1989) assevera que Habermas (1981), em Theorie des kommunikativen Handeln, falhava por não compreender o papel do cliente como um papel de gênero, isto é, um papel paradigmaticamente feminino. $\mathrm{O}$ autor negligenciava serem as mulheres as clientes do Estado de Bem Estar Social. De fato, o grande problema decorreria do fato de que, se a teoria da ação comunicativa poderia constituir um substrato teórico capaz de demonstrar como as esferas pública e privada estariam conectadas, para Fraser (1989), entretanto, a tese da colonização do mundo da vida promoveria uma separação "ideológica" entre as esferas. Por este motivo, a autora demonstra que a família, enquanto espaço de reprodução simbólica, também pode ser vista como um sistema econômico e permeada por relações de poder.

Sob esse prisma, a racionalidade comunicativa poderia contrapor-se aos imperativos sistêmicos ou seria restringida por estas? Nessa concepção crítica, Fraser (1989) destacava que a teoria habermasiana não tinha potencialidade em acomodar as circunstâncias e necessidades específicas do feminismo, porquanto havia uma separação analítica entre os domínios público e privado. Em Faktizität und Geltung, o filósofo alemão (1992a) rompe com a tradição

\footnotetext{
3 É oportuno ilustrar o pensamento de Fraser: "A cegueira de gênero do modelo obscurece importantes características dos arranjos que ele pretende compreender. Ao omitir qualquer menção à função de educação infantil e ao falhar em tematizar o subpapel de gênero subjacente às regras do trabalhador e do consumidor, Habermas falha em compreender precisamente como o local de trabalho capitalista é conectado ao núcleo familiar moderno, restrito, e chefiado por homens. Da mesma forma, ao falhar em tematizar o papel masculino da função de cidadão, ele não atinge o pleno significado da forma como o Estado é ligado à esfera pública de participação política. Além disso, Habermas perde importantes conexões recíprocas entre os quatro elementos dos seus dois esquemas público-privado. Ele não contempla, por exemplo, a forma como o papel masculino do cidadão-soldado-protetor liga o Estado e a esfera pública, não somente um ao outro, mas também liga família e o mercado remunerado, isto é, implica a forma como as pressuposições da capacidade do homem em proteger e a necessidade das mulheres de proteção dos homens atravessa todas essas esferas. Ele perde de vista, também, a forma como o papel masculino do cidadão-participante liga-se ao Estado e à esfera pública, não apenas um em relação ao outro, mas também à família e à economia oficial, isto é, a forma como as pressuposições da capacidade do homem de falar e consentir e a incapacidade das mulheres a esse respeito permeia todas essas esferas. Ele não vislumbra também a forma como o papel masculino do trabalhador-provedor liga a família e a economia oficial, não apenas um em relação ao outro, mas também o Estado e a esfera pública política, isto é, a forma como as pressuposições do status de homem provedor e o status da mulher dependente atravessa todas essas esferas." (FRASER, 1989, p. 117).
}

SCIENTIAIURIS, Londrina, v.18,n.1,p.153-180,jul.2014 | DOI: 10.5433/2178-8189.2014v18n1p153 
liberal, ao estabelecer a cooriginariedade entre as autonomias pública e privada, sendo capaz de responder aos desafios propostos pelas críticas feministas de forma coerente.

Sob essa ótica, em Faktizität und Geltung, Habermas (1992a) procura contrapor-se a perspectivas liberais mediante um modelo discursivo de esfera pública capaz de acomodar as lutas por reconhecimento, conectando a esfera pública com a privada. Sua perspectiva, entretanto, pretende assegurar às mulheres o exercício da autonomia pública na discussão dos papéis de gênero, conferindo-lhes plena oportunidade de participarem de processos discursivos, visando a esclarecer suas necessidades. ${ }^{4}$

Outro aspecto fundamental que distinguia as perspectivas teóricas de Fraser (1992) e Habermas (1992a) dizia respeito à concepção de espaço público. Na concepção habermasiana que foi configurada em Faktizität und Geltung, espaço público constitui um lugar no qual os cidadãos deliberam sobre objetivos comuns, ou seja, uma arena institucionalizada de interação discursiva, conceitualmente distinta do Estado. Mister se faz salientar que, para Fraser (1992), em contraposição à ótica habermasiana (1992a) estabelecida em Faktizität und Geltung, as diferenças entre os parceiros de interação não

${ }^{4}$ Em Faktizität und Geltung, Habermas (1992a)elucida duas concepções que são fundamentais à sua construção teórica: esfera pública e sociedade civil. Nesse sentido, a sociedade civil é a esfera pública institucionalizada. O núcleo institucional da sociedade civil é formado por associações, organizações livres, não estatais e não econômicas, as quais ancoram as estruturas de comunicativas da esfera pública nos componentes sociais do mundo da vida. A sociedade civil compõe-se de movimentos, organizações e associações, os quais captam os ecos das sociais que ressoam nas esferas privadas, condensam-nos e os transmitem, a seguir, para a esfera pública política.

Sob esse aspecto, para Habermas (1992a), há, no núcleo da sociedade civil, a institucionalização de discursos que buscam soluções para problemas que se transformam em questões de interesse geral no âmbito de esferas públicas, conduzindo-os para a esfera política. A esfera pública passa a ser concebida como um sistema de alarme dotado de sensores sensíveis que irá perceber, problematizar e tematizar determinados problemas de modo a serem assumidos pelo poder legislativo, convertendoos em leis.

Ao ensejo, os processos democráticos funcionam como filtros que selecionam temas e contribuições, que são sintetizados pelos fluxos comunicacionais, transformando-se em opiniões públicas sobre temas específicos. A capacidade de influência política que os atores alcançam sobre a comunicação pública deve fundamentar-se em um assentimento de um público de sujeitos privados, que devem ser convencidos por meio de argumentos compreensíveis e razoáveis, sendo tal autoridade intrínseca à estrutura interna da esfera pública.

Com efeito, Habermas (1992a), em Faktizität und Geltung, assinala que a esfera pública possui uma dupla dimensão, sendo formada pelos atores sociais que participam da esfera pública e aqueles que se utilizam da esfera pública formada, visando dominá-la como, por exemplo, os grandes grupos de interesse que agem estrategicamente. Ademais, ninguém pode ser legitimamente excluído desses processos deliberativos e não pode haver coações externas, garantindo-se a integridade dos pressupostos comunicativos. Inexistem também coações internas, uma vez que todos os participantes são tratados como livres e iguais, podendo introduzir, questionar e problematizar temas e contribuições.

SCIENTIAIURIS,Londrina, v.18,n.1,p.153-180,jul.2014 | DOI: 10.5433/2178-8189.2014v18n1p153 
podem ser neutralizadas por práticas dialógicas, com base na força do melhor argumento, pois tal perspectiva apenas reforça a dominação sobre grupos menos poderosos.

Nesse quadro teórico, para Habermas (1992a), em Faktizität und Geltung, superar a ausência de reconhecimento pressupõe que cada indivíduo articule na esfera pública a experiência de dominação e desrespeito resultante violação da autonomia privada. Nas palavras de MacKinnon (2013, p. 9), em suas reflexões sobre a estratégia habermasiana estabelecida em Faktizität und Geltung, "discussões sobre novos padrões de tratamento, sobre como mudar condições existentes, surgem com base em discussões das experiências concretas. " Portanto, para Habermas (1992a), o exercício da autonomia pública é pressuposto para garantia da autonomia privada, pois "tentativas de regular causas de violação à autonomia privada, em si mesmas, não promovem suficientemente tal autonomia." (MACKINNON, 2013, p. 9).

A proposta habermasiana (1992a) de lutas por reconhecimento, estabelecida em Faktizität und Geltung, pressupunha que a possibilidade de engajamento na esfera pública não dependia da existência ou não de obstáculos ao reconhecimento decorrentes do exercício da dominação de status. Habermas (1992a) presumia que grupos minoritários, mesmo em um contexto de ausência de reconhecimento, teriam acesso à esfera pública. Não obstante, como postula MacKinnon (2013), muitas vezes, o exercício da autonomia pública é minado pela recusa de reconhecimento. Para Fraser (1992), é necessário explicitar e tematizar publicamente as desigualdades, assimetrias e não imaginar que estas seriam suspensas no espaço público.

Desse modo, para Fraser (1992), o pressuposto fundamental para a participação paritária constitui a eliminação sistemática das desigualdades de status, de forma que as políticas de reconhecimento devem objetivar a realização da igualdade de status para todos os membros da sociedade. Nesse quadro teórico, de acordo com a autora (1992), os obstáculos à participação paritária podem persistir ainda que os indivíduos tenham a oportunidade de integrar processos deliberativos, porquanto, em diversas situações, "a deliberação pode servir como uma máscara para a dominação". (FRASER, 1992, p. 119).

Para Fraser (1992), frequentemente, os grupos subordinados são impedidos de expressar plenamente suas necessidades e ideias no espaço público mediante formas sutis de controle. É de se mencionar que, em face de um contexto de exclusão do espaço público oficial, a autora (1992) propõe expandir 
as arenas discursivas e, nesse ponto, assume especial relevância sua crítica ao modelo discursivo. Fraser pretende demonstrar que uma concepção de esfera pública deve conter "não a exclusão, mas a inclusão de interesses e questões que a ideologia masculina e burguesa rotula como privadas e trata como inadmissíveis". (FRASER, 1992, p. 137).

Nesse cenário, a teórica feminista enfatiza as formas pelas quais as desigualdades penetram na deliberação do espaço público. Argumenta que a qualificação de algumas questões como privadas limita o escopo dos problemas que podem ser contestados nas sociedades contemporâneas. Nessa perspectiva, somente a partir da compreensão dessa multiplicidade de contrapúblicos subalternos seria possível desenvolver uma análise mais coerente com a contraposição entre o espaço público dominante e os contextos socialmente fragmentados de reprodução de um contrapúblico de resistência. Nas palavras de Fraser, "não é possível isolar arenas discursivas especiais dos efeitos da desigualdade social, e se estas persistem, processos deliberativos nas esferas públicas tenderão a reproduzir a desvantagem dos grupos dominantes e as desvantagens dos subordinados." (FRASER, 1992, p. 122123). Tais efeitos serão potencializados quando há apenas um espaço público único e compreensivo.

Diante dessa estrutura conceitual, para Maria Pia Lara e Robert Fine, "públicos concorrentes são parte crucial do conceito emancipatório de esfera pública, sendo capaz de reagir contra exclusão e desenvolver demandas por inclusão social justamente por não serem parte de uma esfera pública mais geral. “(LARA; FINE, 2007, p. 38). Embora Fraser enfatize a função contestatória do contrapúblico, ela não os compreende como processos que não poderiam implicar demandas de inclusão. (LARA; FINE, 2007, p. 39). Fraser (1992) conclui que grupos excluídos que veem a si próprios como formando trincheiras de resistência ainda necessitam ter um programa com objetivos emancipatórios. A noção gramsciana de hegemonia associa-se à sua concepção de público subalterno inspirando arenas discursivas cada vez mais amplas.

Outrossim, tais críticas tiveram repercussão na concepção habermasiana (1992b) de esfera pública que terminou por redimensionar sua percepção inicial. Habermas (1992b), no ensaio "Further Reflections on the Public Sphere", passou a admitir a coexistência de esferas públicas concorrentes, analisando as dinâmicas dos processos de comunicação que são excluídos da esfera pública dominante. Argumenta que a existência de 
múltiplas esferas permite um acesso mais abrangente à esfera pública. A esfera pública seria uma rede discursiva instituída por uma multiplicidade de públicos transversais sobrepostos e em dimensões diversas, mas articulada por algum aspecto quanto a conteúdo, relações sociais, etc. (Habermas, 1992b, p. 425).

Em suma, surgem esferas públicas literárias, feministas, artísticas. Em $A$ Berlin Republic, Habermas (1997) pondera que o acesso à esfera pública é um pressuposto para lutas por reconhecimento, ou seja, uma condição fática que viabiliza a igual oportunidade de exercício formal dos direitos. No entanto, ao mesmo tempo, parece reconhecer situações em que o acesso à esfera pública encontra-se inviabilizado. Como salienta MacKinnon (2013), há casos em que os grupos minoritários precisam, em primeiro lugar, lutar para expandir os horizontes da esfera pública para, posteriormente, se engajar em lutas por reconhecimento.

Em A Berlin Republic, Habermas (1997) renova sua estrutura conceitual, resgatando a categoria da "subclasse" para tratar de grupos radicalmente excluídos da participação na esfera pública em razão de mecanismos de dominação e subordinação. Desigualdades materiais extremas e concentração de poder nas mãos de alguns são diagnosticados por Habermas (1997) como obstáculos ao engajamento na esfera pública. A nova reflexão habermasiana sobre a categoria relativa à "subclasse" pressupõe que, embora as discussões na esfera pública tenham potencialidade para desconstruir relações de dominação, muitas vezes, são estas últimas que impedem o acesso à esfera pública.

\section{ESFERA PÚBLICA TRANSNACIONAL EM HABERMAS E FRASER}

De fato, segundo Fraser (2009), as decisões tomadas em um Estado territorial, as ações das corporações transnacionais, dos especuladores financeiros produzem impactos sociais que transcendem as fronteiras territoriais. As organizações supranacionais e internacionais e a opinião pública transnacional emergem de forma a transcender as fronteiras territoriais. Inicialmente, o enquadramento keynesiano-westfaliano assumia como premissa que $o$ quem correspondia aos cidadãos nacionais. Com a globalização e instabilidades geopolíticas, esse enquadramento vem deixando de ser uma premissa autoevidente. 
Sob essa ótica, a categoria esfera pública situada territorialmente sofre uma revisão crítica à luz de uma abordagem transnacional. ${ }^{5}$ Em Scales of Justice, Fraser (2009) defende uma Teoria da Justiça Democrática pósWestfaliana tridimensional, capaz de contemplar a dimensão política da representação ao lado das dimensão cultural do reconhecimento e da dimensão econômica da redistribuição.

Por fim, há um terceiro nível de justiça política que ultrapassa a temática do o que e do quem e que incorpora a questão do como. A falsa representação metapolítica surge quando Estados e elites transnacionais monopolizam a atividade de estabelecimento do enquadramento, fracionando o espaço político e impedindo a deliberação dos afetados no processo em esferas públicas democráticas nas quais as reivindicações pudessem ser tematizadas e contempladas. Os movimentos sociais, ao afirmarem seu direito de deliberar na constituição do quem da justiça, eles terminam por transformar o como. ${ }^{6}$

Com efeito, para Fraser (2009), Habermas (1992a), em em Faktizität und Geltung, estava preocupado com a questão da eficácia e do déficit de

\footnotetext{
Sob esse prisma, há uma desestabilização da estrutura de formulação de demandas políticas e do modo de discussão de justiça social. Na sociedade global, não basta refletir sobre o que a justiça requer, mas quem satisfaz às condições para reivindicação. Se antes estava em disputa $o$ que é devido aos membros da comunidade, agora discute-se sobre quem deve contar como membro e qual é a comunidade relevante. Portanto, não se trata apenas de discutir as demandas dos movimentos sociais, mas quem são os atores sociais legitimados. Nesse ponto, Fraser (2010) alega que a teoria da justiça para tempos anormais deve rejeitar pressuposições cientificas. Fatos incontroversos quanto a quem é afetado, decorrentes de interpretações dos historiadores, teorias sociais e pressuposições normativas também são objeto de discussão. As questões do quem transcendem a moldura keynesiana- westfaliana dos públicos nacionais, sendo submetidas a um processo dialógico que irá delimitar as reivindicações dos desfavorecidos. Segundo a autora (2009), preocupada com a temática do reconhecimento e da distribuição, a maioria das teorias contemporâneas não consegue estabelecer um instrumental teórico que contemple a meta questão do enquadramento. No entanto, nas sociedades globais, as hierarquias de status não se restringem mais à soberania estatal e as injustiças econômicas cada vez mais ultrapassam o Estado nacional.

É mister frisar que, anteriormente a Scales of Justice, Fraser (2003) havia analisado dois tipos distintos de injustiça enquanto obstáculos à participação paritária: a injustiça distributiva e o falso reconhecimento, pois ambos não permitem que os indivíduos possam interagir em termos de paridade. A justiça demanda arranjos sociais que permitem a todos os indivíduos participarem como pares na vida social. A injustiça, por sua vez, é combatida por meio da desconstrução dos mecanismos institucionais que impedem alguns sujeitos de participar em condições de paridade com os demais, como parceiros plenos da interação social. Ao assumir o enquadramento keynesiano como pressuposto inquestionável, distribuição e reconhecimento eram as únicas dimensões da justiça.

Nesse sentido, Fraser (2003a) defendia que o falso reconhecimento não poderia ser compreendido como um efeito secundário da má distribuição, e esta também não poderia ser reduzida a uma expressão do falso reconhecimento. Ao questionarmos a questão do enquadramento, surge uma terceira dimensão da justiça: o político.

${ }^{6}$ No ensejo, na sociedade global, as lutas por justiça não têm sucesso se não se desenvolverem de maneira articulada com "lutas por democracia metapolítica." O princípio da paridade participativa envolve a concepção de resultado "que especifica o princípio substantivo da justiça pelo qual
} 
legitimidade da opinião pública nos Estados democráticos. O direito seria o instrumento capaz de traduzir o poder comunicativo para o poder administrativo. Nas palavras de Fraser, Habermas "distingue uma circulação de poder pública, democrática, na qual públicos fracos influenciam públicos fortes, que, por sua vez, controlam o aparato estatal administrativa da circulação de poder não pública e não democrática, na qual poderes sociais privados e interesses burocráticos entrincheirados controlam a produção legislativa e manipulam a opinião pública". (Habermas, 1992 apud FRASER, 2009, p. 84).

Nesse quadro teórico, reconhecendo que a circulação não pública geralmente prevalece, em Faktizität und Geltung, Habermas (1992a), nas palavras de Fraser, estabelece uma "concepção mais completa sobre os déficits de eficácia da opinião pública nos Estados democráticos”. (FRASER, 2009, p. 85). Todavia, apesar das modificações introduzidas em Faktizität und Geltung, para Fraser (2009), Habermas (1992a) não consegue superar a estrutura keynesiana-westfaliana, vinculando a ideia de opinião pública ao âmbito da jurisdição soberana estatal. A autora (2009) destaca que Habermas (1998), apesar de reconhecer uma forma pós-nacional de integração social, que pretende uma emancipação do Estado democrático de uma cidadania etnocultural, termina por endossar uma concepção de publicidade exclusivamente territorial.

Em verdade, até 2011, havia uma ambiguidade nos seus escritos sobre a Europa. Segundo Boon (2007), Habermas oscilava entre a proposta de um modelo prescritivo fino de patriotismo constitucional e o apelo a uma noção forte de autocompreensão europeia. Essa tensão entre a abordagem fina e densa se revela na própria interpretação habermasiana (2006a), segundo a qual cada comunidade política interpreta princípios constitucionais à luz de sua própria história. $^{7}$

podemos avaliar arranjos sociais: estes últimos só são justificados se permitirem que todos os atores sociais relevantes participem como pares na vida social". (FRASER, 2009, p. 37). Por outro lado, a participação paritária contempla a noção de processo, que determina um padrão procedimental segundo o qual é possível avaliar o nível de legitimidade democrática da norma. Estas só são legítimas se contarem com "o assentimento de todos os concernidos em um processo de deliberação justo e aberto, capaz de estabelecer uma relação de paridade para todos." (FRASER, 2009, p. 37). A paridade participativa problematiza tanto a substância como o procedimento.

7 Não obstante, Habermas (1998) tem paulatinamente desenvolvido uma estrutura conceitual que vai além do modelo fino de integração política, passando a defender uma concepção particular de autocompreensão europeia. Em Inclusion of the Other, o autor (1998) defende que não poderá haver um Estado federativo europeu se não for estabelecido no horizonte de uma cultura política, uma opinião pública em âmbito europeu, uma sociedade civil com associações representativas de interesses, organizações não estatais, movimentos de cidadania, um sistema político partidário concebido em face de arenas europeias, em suma, um contexto comunicativo que transcenda as fronteiras de opiniões públicas de inserção meramente nacional.

SCIENTIAIURIS, Londrina, v.18,n.1,p.153-180,jul.2014 | DOI: 10.5433/2178-8189.2014v18n1p153 
Em face desta leitura, em Sobre a constituição da Europa - um ensaio, Habermas (2012) finalmente soluciona tal ambiguidade em sua obra. Até então, Habermas limitava-se a denunciar a incapacidade dos Estados nacionais em administrar o mercado global e a apontar o déficit democrático da integração europeia e suas instituições, mas ainda pressupunha o Estadonação como a esfera pertinente para a prática democrática. Agora, Habermas (2012) sublinha, de forma mais clara, que as instituições transnacionais somente alcançam legitimidade quando garantem a formação democraticamente estruturada de opinião e de vontade dos cidadãos europeus. Estes atuam como cidadãos de seus países e como cidadãos europeus em uma democracia mundial. ${ }^{8}$

Diante dessa estrutura conceitual, com a complexidade política da sociedade mundial, que limita a esfera de ação dos Estados nacionais, estes não conseguem mais solucionar determinados problemas complexos, recorrendo a organizações internacionais. Para Habermas (2012), a única maneira que os Estados nacionais têm de se contraporem às coerções sistêmicas da sociedade mundial seria ampliar a esfera pública por meio de uma transnacionalização da soberania popular.

Portanto, não seria suficiente que as competências transferidas do Estado nacional para as instâncias supranacionais sejam apenas juridificadas na forma de tratados internacionais. Tais competências deveriam ser juridificadas de forma democrática. Cidadãos de um Estado afetado devem

Desse modo, essa tendência teórica voltada para uma concepção densa de identidade europeia se intensificou desde 2006, quando, por motivos pragmáticos, defende que a solidariedade europeia não pode ser mantida apenas por condições econômicas, demandando uma forma de legitimação por valores compartilhados (Habermas, 2006b, p. 92). Valores culturais compartilhados podem ser alcançados através de esferas públicas nacionais interconectadas nas quais questões relevantes são debatidas.

Não obstante, segundo Boon (2007, p. 7), essas formações discursivas ainda são situadas no background de autocompreensões ético-políticas compartilhadas, de forma que a solidariedade estabelecida possui efetivamente uma dimensão espessa. Em Divided West, Habermas (2006a, p. 43) questiona: o que é uma identidade europeia? Nesse cenário, analisa "as experiências históricas, tradições e realizações capazes de promover entre os cidadãos europeus um sentido de destino político compartilhado que eles podem construir em comum. (HABERMAS, 2006a, p. 43). No entanto, como salienta Boon (2007), a noção de identidade europeia não é compartilhada por toda a Europa e poderia tornar-se mais excludente do que efetivamente pretendia.

8 Habermas (2012)sublinha que haveria, na União Europeia, um desequilíbrio entre os imperativos dos mercados e a força regulatória da política. Segundo Habermas (2012), existiriam atualmente dois projetos diversos de Europa. O primeiro corresponde à proposta de tornar a União Europeia um Conselho Europeu, no qual os Chefes de Estado dos países deliberam sobre diversas temáticas, minimizando o papel dos parlamentos nacionais e criando um modelo de federalismo executivo. As decisões políticas mais relevantes seriam tomadas por burocratas e não pela formação democrática da opinião e da vontade dos cidadãos europeus.

SCIENTIAIURIS,Londrina, v.18, n.1,p.153-180, jul.2014 | DOI: 10.5433/2178-8189.2014v18n1p153 
ter a oportunidade de deliberarem juntamente com cidadãos dos demais Estados em um procedimento democrático de criação de uma legislação supranacional. Dessa maneira, Habermas aposta em uma forma transnacionalmente ampliada de solidariedade civil. O Tratado de Lisboa "deveria fortalecer a capacidade de ação da União Europeia com a incorporação do Conselho Europeu na estrutura institucional". (HABERMAS, 2012, p. 81). O autor (2012) defende que, a partir da criação de uma Constituição Europeia, seria possível vislumbrar uma cooperação constituinte entre cidadãos e estados na qual a comunidade internacional existente entre Estados seria complementada por uma comunidade cosmopolita. ${ }^{9}$

Outrossim, o Parlamento mundial, enquanto intérprete da Carta das Nações Unidas, deveria levar em consideração essa dupla perspectiva. A comunidade mundial não possuiria mais um caráter estatal, devendo os Estados se subordinar às resoluções do Conselho de Segurança. Os Estados membros não se autocompreenderiam mais como membros solidários da comunidade internacional. Defende que o Parlamento mundial deveria "orientar os debates sobre as condições do fundo da justiça global, e o Conselho de Segurança tomaria as decisões importantes, sendo estas, porém, amplamente judicializadas e controladas pelas Cortes." (HABERMAS, 2012, p. 101). O autor defende um contexto comunicativo global inspirado numa esfera pública renovada que, a partir da tecnologia digital, permitiria a todas as populações a formação de um juízo moralmente justificado sobre o conteúdo das decisões tomadas no âmbito das Nações Unidas.

\section{CONSIDERAÇÕES FINAIS}

Diante do exposto, depreende-se que a grande renovação teórica fundamental da estrutura conceitual de esfera pública na obra habermasiana é

\footnotetext{
${ }^{9}$ É clara a assertiva de Habermas (2012, p. 95): “Os Estados nacionais formariam, ao lado dos cidadãos do mundo, o segundo sujeito constituinte da comunidade mundial. Pois os cidadãos cosmopolitas têm ou teriam ainda boas razões para se ater ao papel constitutivo de seus estados em todo o âmbito supranacional. Na medida em que os cidadãos já realizaram nessas formas históricas uma parte da justiça política escoada institucionalmente, eles podem nutrir o desejo fundamentado de que seus estados nacionais se mantenham como entidades coletivas nos respectivos níveis superiores de organização. A composição de uma Assembléia geral de representantes dos cidadãos e dos Estados asseguraria que as perspectivas concorrentes sobre a Justiça fossem levadas em consideração pelos cidadãos do mundo, por um lado, e pelos cidadãos do Estado, por outro, alcançando assim um equilíbrio. “
}

SCIENTIAIURIS, Londrina, v.18, n.1,p.153-180, jul.2014 | DOI: 10.5433/2178-8189.2014v18n1p153 
estabelecida no prefácio de 1990 à Strukturwandel der Öffentlichkeit (1990), mas a sua função mais proeminente é ampliada em Faktizität und Geltung (1992) a partir de um modelo de eclusas. Não se trata de um modelo baseado na ideia de sitiamento, estabelecida em Theorie des kommunikativen Handelns, mas um processo de autodemocratização interno do sistema. Surge uma nova percepção sobre a relação entre poder comunicativo e poder administrativo instituído no sistema político.

Para Fraser (1992), todavia, o modelo habermasiano necessitava ser reconstruído para contemplar novos aspectos necessários ao desenvolvimento de projetos alternativos de democracia. Em síntese, o modelo de esfera pública liberal que foi desenvolvido por Habermas (1962) em Strukturwandel der Öffentlichkeit, era notadamente idealizado. Fraser (1992) contrapôs-se à concepção habermasiana de espaço público, no sentido de ser necessário criar condições institucionais - seja na esfera do reconhecimento ou da redistribuição - para que os indivíduos possam interagir como parceiros políticos.

De fato, para FRASER (1992, p. 122-123), como os membros dos grupos subordinados nem "sempre teriam arenas para deliberar entre si próprios sobre suas necessidades, objetivos e estratégias", uma pluralidade de públicos concorrentes tem maior potencialidade em promover o ideal da participação paritária, diferentemente de um público único, compreensivo. Com a noção de contrapúblico, "Fraser desenvolve uma ideia mais dinâmica de lutas sociais ao mesmo tempo em que acrescenta uma dimensão mais política à noção de esfera pública". (LARA; FINE, 2007, p. 38).

Sob essa ótica, Fraser (1998) insiste na necessidade de compreender tais estratégias de poder como políticas e de como processos de legitimação em debates públicos quebram desigualdades de status das mulheres. Concluímos, com base em Fraser (1998) e nas reformulações teóricas habermasianas (1992b), pela necessidade de eliminar as disparidades sociais e diferenças de gênero, o que somente se efetivaria por meio da constatação de certos públicos alternativos que inspiram a circulação de discursos de oposição de grupos excluídos da esfera pública oficial.

É justamente nas arenas discursivas, estabelecidas pelos contrapúblicos subalternos, que as feministas têm articulado, de forma mais renovada, a compreensão acerca de sua realidade, no que se refere à 
discussão de temas relacionados ao casamento, assédio sexual, divórcio, minimizando a profunda situação de desvantagem na esfera pública oficial. No entanto, apesar da referida renovação teórica estabelecida em Faktizität und Geltung, Habermas (1992a)não havia superado a estrutura westfaliana, situando a esfera pública no âmbito territorial. Havia, na sua obra, uma ambiguidade que oscilava entre a abordagem fina de patriotismo constitucional e a concepção densa de autocompreensão europeia.

Com efeito, em Sobre a constituição da Europa - um ensaio, Habermas (2012) soluciona tal ambiguidade, lecionando que as instituições transnacionais somente se tornam legítimas quando estabelecem um processo democraticamente estruturado de opinião e de vontade. A renovação da categoria esfera pública se efetiva à medida que Habermas defende que os cidadãos, por meio da tecnologia digital e de padrões morais, avaliam as estruturas econômicas europeias, confrontando as instituições existentes com as exigências de uma justiça global. Tais discussões devem ser efetivadas no interior de um Parlamento mundial composto de Estados e cidadãos.

\section{REFERÊNCIAS}

BOON. Vivienne. Habermas's Jürgen's Writings on Europe: not Habermasian Enough. Ethical Perspectives, vol. 14, n. 3. European Centre for Ethics. Leuven, 2007, p. 287-310.

FRASER, Nancy. What's Critical about Critical Theory? The Case of Habermas and Gender. In: Unruly Practices: Power, Discourse and Gender in Contemporary Social Theory. Minneapolis: University of Minnesota Press, 1989.

. Rethinking the Public Sphere: a Contribution to the Critique of Actually Existing Democracy. In: CALHOUN, Craig. Habermas and the Public Sphere. Cambridge: Mit Press, 1992.

. What's Critical about Critical Theory? The Case of Habermas and Gender. In: MEEHAN, Johann (ed.). In:Feminist Read 
Habermas: Gendering the Subject of Discourse. New York: Routledge, 1995.

. Distorted Beyound all Recognition: A Rejoinder to Axel Honneth. In: FRASER, Nancy; HONNETH, Axel. Redistribution or Recognition?-A Political Philosophical Exchange. London: Verso, 2003.

HABERMAS, Jürgen. Strukturwandel der Öffentlichkeit. Berlin / Neuwied: Luchterhand, 1962.

. Theorie und Práxis: Sozialphilosophische Studien. Berlin / Neuwied: Luchterhand, 1963.

. Technik und Wissenschaft als Ideologie. Frankfurt: Suhrkamp, 1968.

. Theorie und Práxis: Sozialphilosophische Studien. Frankfurt: Suhrkamp, 1971.

. Legitimationsproblem im Spätkapitalismus. Frankfurt:

Suhrkamp, 1973.

. Theorie des kommunikativen Handelns. Frankfurt:

Suhrkamp, 1981.

. Theorie des kommunikativen Handelns. Frankfurt:

Suhrkamp, 1985.

. Theorie des kommunikativen Handelns. Frankfurt:

Suhrkamp, 1986.

. Strukturwandel der Öffentlichkeit. Frankfurt: Suhrkamp, 1990 (Vorwort zur Neuauflage).

. Faktizität und Geltung: Beiträge zur Diskurstheorie des Rechts und des Demokratischen Rechtsstaats. Frankfurt: Suhrkamp, 1992a. 
. Further Reflections on the Public Sphere. In: Habermas and the Public Sphere. Cambridge, Massachusetts and London: The Mit Press, $1992 b$.

A Berlin Republic: Writings on Germany. Lincoln: University of Nebraska Press, 1997.

. Inclusion of the Other: Studies in Political Theory. Cambridge: Polity, 1998.

- ¿Por qué Europa necesita una Constitución ? New Left Review (edición española), n. 11, Madrid, Novembro-Dezembro de 2001. Disponível em: $<$ http://newleftreview.es/authors/jurgen-habermas $>$. Acesso em 1/1/2014.

. Era das transições. Trad. e introdução Flávio Siebeneichler. Rio de Janeiro: Tempo Brasileiro, 2003.

. The Divided West. Cambridge: Polity, 2006a.

. Time of Transitions. Cambridge: Polity, 2006b.

LARA, María Pia and FINE, Robert. Justice and Public Sphere. The Dynamics of Nancy Fraser's Critical Theory. In: LOVELL, Terry (org.). (Mis)recognition, Social Inequality and Social Justice: FRASER, Nancy and Bourdieu. Abingdon, New York: Routledge, 2007, p. 36-48.

LUBENOW, Jorge Adriano. A Categoria de Esfera Pública em Jürgen Habermas. Tese de Doutorado. Departamento de Filosofia do Instituto de Filosofia e Ciências Humanas. Universidade Estadual de Campinas, 2007.

- A Despolitização da esfera pública em Jürgen Habermas sob a perspectiva sócio-política. Problemata, vol. 3, n. 1, João Pessoa, 2012, p. 54-95.

MACKINNON, Emma Stone. Beyond Recognition: Habermas's 'Constitutional Patriotism' as a response to Exclusion from the Public Sphere. 
Political Theory Workshop. Chicago: University of Chicago, November, 2013. Disponível em: < http://ptw.uchicago.edu/Mackinnon13.pdf>. Acesso em $1 / 1 / 2014$.

Artigo recebido em: 05/06/2014 Aprovado para publicação em: 17/07/2014

Como citar: BUNCHAFT, Maria Eugenia. Esfera pública, reconhecimento e minorias: o diálogo Habermas-Fraser. Scientia Iuris, Londrina, v.18, n.1, p.153-180, jul.2014. DOI: 10.5433/2178-8189.2014v18n1p153. 